\title{
EFFECT OF A SURGICAL CARE BUNDLE ON THE INCIDENCE OF SURGICAL SITE INFECTION IN COLORECTAL SURGERY: A QUASI-EXPERIMENTAL INTERVENTION
}

\author{
Leire Zarain-Obrador ${ }^{1}$, Marcos Alonso-García ${ }^{2,3}$, Pablo Gil-Yonte ${ }^{4}$, Ana I. Hijas-Gómez ${ }^{5}$, \\ Diego Rodríguez-Villar ${ }^{3}$, Brezo Martínez-Amores ${ }^{3}$, Ángel Gil-de-Miguel ${ }^{3}$, Jaime Ruiz-Tovar ${ }^{1,3}$, \\ Gil Rodríguez-Caravaca ${ }^{2,3 *}$, and Manuel Durán-Poveda ${ }^{1,3}$ \\ ${ }^{1}$ Department of Surgery, Rey Juan Carlos Hospital, Móstoles, Madrid; ${ }^{2}$ Department of Preventive Medicine, \\ Alcorcón Foundation University Hospital, Alcorcón, Madrid; ${ }^{3}$ Department of Medical Specialties and Public Health, \\ Rey Juan Carlos University, Alcorcón, Madrid; ${ }^{4}$ Department of Surgery, Alcorcón Foundation University Hospital, \\ Alcorcón, Madrid; ${ }^{5}$ Health Technology Assessment Agency (AETS), Carlos III Institute of Health, Madrid, Spain
}

\begin{abstract}
Background: Surgical site infections (SSI) have an important impact on morbidity and mortality. Objective: This study, therefore, sought to assess the effect of a surgical care bundle on the incidence of SSI in colorectal surgery. Methods: We conducted a quasi-experimental intervention study with reference to the introduction of a surgical care bundle in 2011. Our study population, made up of patients who underwent colorectal surgery, was divided into the following two periods: 2007-2011 (pre-intervention) and 2012-2017 (post-intervention). The intervention's effect on SSI incidence was analyzed using adjusted odds ratios (OR). Results: A total of 1,727 patients were included in the study. SSI incidence was $13.0 \%$ before versus $11.6 \%$ after implementation of the care bundle (OR: $0.88,95 \%$ confidence interval: $0.66-1.17, p=0.37$ ). Multivariate analysis showed that cancer, chronic obstructive pulmonary disease, neutropenia, and emergency surgery were independently associated with SSI. In contrast, laparoscopic surgery proved to be a protective factor against SSI. Conclusions: Care bundles have proven to be very important in reducing SSI incidence since the measures that constitute these protocols are mutually reinforcing. In our study, the implementation of a care bundle reduced SSI incidence from $13 \%$ to $11.6 \%$, though the reduction was not statistically significant. (REV INVEST CLIN. 2021;73(4):251-8)
\end{abstract}

Key words: Surgical site infection. Incidence. Care bundle. Colorectal surgery.

\section{INTRODUCTION}

Surgical site infections (SSIs) are an important problem in public healthcare, giving rise to high morbidity, mortality, prolonged hospital stays, and an ensuing financial impact. These factors are especially relevant in the case of colon surgery since SSI incidence is higher in this field than in other surgical subspecialties $^{1-4}$. SSIs are defined as infections related to a surgical procedure, which affect the surgical incision or
*Corresponding author:

Gil Rodríguez-Caravaca

E-mail: grodriguez@fhalcorcon.es
Received for publication: 26-01-2021

Approved for publication: 07-04-2021

DOI: $10.24875 / R I C .21000067$

0034-8376 / (c) 2021 Revista de Investigación Clínica. Published by Permanyer. This is an open access article under the CC BY-NC-ND license (http://creativecommons.org/licenses/by-nc-nd/4.0/). 
surrounding tissues during the surveillance period, set at 30 days after surgery if no implant is used, or up to 3 months if a prosthetic implant has been placed in situ ${ }^{5-7}$. SSIs are one of the main causes of nosocomial infections, accounting for more than $20 \%$ of all hospital-acquired infections, and currently rank as the most frequent nosocomial infection in patients who have undergone surgery ${ }^{8-10}$.

Taking into account the National Research Council classification of surgical procedures by reference to the risk of infection ${ }^{11}$, there are three types of SSIs that can be distinguished according to their localization $^{12}$, that is, superficial, deep, and organ-space SSIs. Somewhere between $2 \%$ and $5 \%$ of all patients who undergo surgery will develop an $\mathrm{SSI}^{13}$, with the risk of SSIs being even greater in the case of colorectal surgery ${ }^{14}$.

According to different guidelines, up to $60 \%$ of infections are preventable by implementing evidencebased recommendations ${ }^{15}$. As a result, different initiatives have been introduced in recent years to reduce the incidence of $\mathrm{SSIs}^{16,17}$. What all of these have in common is the implementation of care bundles, consisting of a series of three or more interventions to be applied in all patients by means of checklists ${ }^{18}$. Indeed, the success of these measures depends on the systematic application of all rather than one or two selective interventions, as each intervention enhances the others ${ }^{19}$. In light of this evidence, in 2011, we implemented a surgical care bundle consisting of a series of measures aimed at reducing the incidence of SSIs. Accordingly, the aim of this study was to evaluate the effect of this surgical care bundle on the incidence of SSIs in colorectal surgery.

\section{METHODS}

\section{Patients and Study Design}

We conducted a quasi-experimental intervention study with a before-and-after analysis, with reference to the introduction of a surgical care bundle made up of four items with scientific evidence of proven effect, recommended by the Spanish Ministry of Health ${ }^{20}$, and analyzed its effect on the incidence of SSI. Our study population comprised patients who had undergone colorectal surgery, as per the National Nosocomial
Table 1. COLO surgical procedures

\begin{tabular}{|c|c|}
\hline $\begin{array}{l}\text { ICD-9_MC } \\
\text { Code }\end{array}$ & Colon surgical procedure description \\
\hline 45.03 & Incision of large intestine \\
\hline 45.26 & Open biopsy of large intestine \\
\hline 45.41 & Excision of lesion or tissue of large intestine \\
\hline 45.49 & $\begin{array}{l}\text { Other destruction of lesion of large } \\
\text { intestine }\end{array}$ \\
\hline 45.52 & Isolation of segment of large intestine \\
\hline 45.71 & $\begin{array}{l}\text { Open and other multiple segmental } \\
\text { resection of large intestine }\end{array}$ \\
\hline 45.72 & Open and other cecectomy \\
\hline 45.73 & Open and other right hemicolectomies \\
\hline 45.74 & $\begin{array}{l}\text { Open and other resection of transverse } \\
\text { colon }\end{array}$ \\
\hline 45.75 & Open and other left hemicolectomies \\
\hline 45.76 & Open and other sigmoidectomies \\
\hline 45.79 & $\begin{array}{l}\text { Other and unspecified partial excision } \\
\text { of large intestine }\end{array}$ \\
\hline 45.80 & Total intra-abdominal colectomy \\
\hline 45.92 & $\begin{array}{l}\text { Anastomosis of small intestine to rectal } \\
\text { stump }\end{array}$ \\
\hline 45.93 & Other small-to-large intestinal anastomosis \\
\hline 46.03 & Exteriorization of large intestine \\
\hline 46.04 & $\begin{array}{l}\text { Resection of exteriorized segment of large } \\
\text { intestine }\end{array}$ \\
\hline 46.10 & Colostomy, not otherwise specified \\
\hline 46.11 & Temporary colostomy \\
\hline 46.13 & Permanent colostomy \\
\hline 46.14 & Delayed opening of colostomy \\
\hline 46.43 & Other revision of stoma of large intestine \\
\hline 46.75 & Suture of laceration of large intestine \\
\hline 46.76 & Closure of fistula of large intestine \\
\hline 46.94 & Revision of anastomosis of large intestine \\
\hline
\end{tabular}

Infections Surveillance/National Healthcare Safety Network (NNIS) COLO category (Table 1), at the Alcorcón Foundation University Teaching Hospital. All patients received a low-residue diet before surgery, oral prophylaxis with neomycin $1 \mathrm{~g}$, and an oral cathartic (Bohm ${ }^{\circledast}$ solution) administered the day before surgery for mechanical bowel preparation. In 2017, the oral cathartic was changed to CitraFleet ${ }^{\oplus}$. Patients received antibiotic prophylaxis with amoxicillinclavulanic 2 g 30-60 min before surgery and $4 \mathrm{~h}$ afterward. Allergic patients received metronidazole $500 \mathrm{mg}$ and gentamicin $3-5 \mathrm{mg} / \mathrm{kg}$. Patients undergoing colorectal surgery were divided into the following two periods: 2007-2011 (pre-intervention); and 
Table 2. Surgical preventive measures care bundle implemented in 2011

Replacement of hygienic and surgical handwashing with chlorhexidine by washing and disinfection with hydroalcoholic solutions

Replacement of surgical field shaving with a razor blade by removal of hair from the surgical field with an electric razor

Antisepsis of the surgical field with $2 \%$ alcoholic chlorhexidine instead of povidone-iodine as was previously used

Prospective surveillance, update, and assessment of surgical antibiotic prophylaxis

2012-2017 (post-intervention). Patients were selected and included consecutively from the surgical schedule listings of the General and Digestive Surgery Department.

Sample size was estimated on the basis of a $95 \%$ confidence level, a statistical power of $80 \%$, an incidence of SSI of $15 \%$ in the non-intervention group and $10 \%$ in the intervention group, and a $5 \%$ loss to follow-up. A sample of at least 1528 patients was thus deemed necessary. The EPIINFO v7 software suite was used to calculate the sample size.

Since an SSI is defined as an infection established within the first 30 days after surgery, patients' progress was recorded from the time of surgery to the end of the maximum incubation period (30 days). The association between risk factors and SSI and the effect of the surgical care bundle on the incidence of infection were assessed by reference to the odds ratio (OR). The component measures of the surgical care bundle developed and drawn up in 2011 are shown in Table 2.

\section{Study Variables}

The variables studied included sex, age, comorbidities (renal failure, diabetes mellitus, cancer, chronic obstructive pulmonary disease (COPD), liver cirrhosis, obesity, and neutropenia), hospital stay, study group ("pre-intervention group" and "post-intervention group"), urgency and duration of surgery, type of surgery (laparoscopic or open), surgical contamination, administration of antibiotic prophylaxis (antibiotic administered, route, dose, start time, and duration) according to the hospital protocol, pre-operative preparation-related aspects (pre-operative antiseptic shower and mouthwash), presence or absence of infection according to the diagnostic criteria of the $\mathrm{CDC}^{6}$, and the microorganisms involved.

\section{Statistical Analysis}

A descriptive analysis of the sample was performed. Quantitative variables were described using either the mean and standard deviation (SD) or the median and interquartile range if they did not meet the conditions of normality. Quantitative variables were compared by means of the Student's t-test or in cases where they did not follow a normal distribution by means of the Mann-Whitney $U$ test. Qualitative variables were described with their frequency distribution and compared with Pearson's Chi-square test or with Fisher's exact test if they did not meet the application criteria.

Antibiotic prophylaxis was defined as correctly used when all the items were administered according to the hospital protocol and inappropriate when any of them were not used correctly.

The cumulative incidence of infection was assessed, both overall and stratified by the NNIS risk index, for the pre-intervention and post-intervention group periods of implementation of the surgical care bundle. The effect of the intervention on SSI incidence was evaluated using the OR and its $95 \%$ confidence interval $(\mathrm{Cl})$ and adjusted for the different covariates with a backward stepwise logistic regression model. Covariates with $p<0.2$ in the univariate analysis or proving clinically relevant were included in the study. All statistical analyses were performed using the SPSS v.24 software package, with values being deemed statistically significant at $p<0.05$.

\section{RESULTS}

The study covered a total of 1727 patients who underwent colorectal surgery, 899 in the period 20072011 and 828 in the period 2012-2017. The characteristics of the patients are shown in Table 3. Patients' mean age was 67.3 years (SD: 14.4 ) in the pre-intervention group and 67.9 years (SD: 13.3 ) in the postintervention group $(p=0.345)$. In terms of gender, 
Table 3. Patient characteristics

\begin{tabular}{|c|c|c|c|}
\hline Variable & $\begin{array}{c}\text { Pre-intervention } \mathrm{n} \\
(\%)\end{array}$ & $\begin{array}{c}\text { Post-intervention } \mathrm{n} \\
(\%)\end{array}$ & $\mathrm{p}$ \\
\hline \multicolumn{4}{|l|}{ Gender } \\
\hline Male & $559(62.2)$ & $484(58.5)$ & 0.114 \\
\hline Female & $340(37.8)$ & $344(41.5)$ & 0.114 \\
\hline Mean age (SD) & $67.31(14.4)$ & $67.94(13.3)$ & 0.345 \\
\hline \multicolumn{4}{|l|}{ Comorbidities } \\
\hline Diabetes mellitus & $162(18)$ & $112(13.5)$ & 0.011 \\
\hline Obesity & $58(6.5)$ & $61(7.4)$ & 0.453 \\
\hline COPD & $59(6.6)$ & $39(4.7)$ & 0.096 \\
\hline Neutropenia & $8(0.9)$ & $7(0.8)$ & 0.921 \\
\hline Cancer & $420(46.7)$ & $441(53.3)$ & 0.001 \\
\hline \multicolumn{4}{|l|}{ NNIS } \\
\hline 1 & $291(32.4)$ & $334(40.3)$ & $<0.001$ \\
\hline 2 & $476(52.9)$ & $392(47.3)$ & $<0.001$ \\
\hline 3 & $132(14.7)$ & $102(12.3)$ & $<0.001$ \\
\hline \multicolumn{4}{|l|}{ Surgical approach } \\
\hline Open & $702(78.1)$ & $528(63.8)$ & $<0.001$ \\
\hline Laparoscopic & $197(21.9)$ & $300(36.2)$ & $<0.001$ \\
\hline Average hospital stay (SD) & $3.05(13.7)$ & $2.69(6.9)$ & 0.505 \\
\hline
\end{tabular}

SD: standard deviation; COPD: Chronic Obstructive Pulmonary Disease; NNIS: National Nosocomial Infections Surveillance risk index.

559 patients were male and 340 were female in the pre-intervention group versus 484 and 344 , respectively, in the post-intervention group.

The most frequent comorbidities among the patients were cancer $(49.8 \%)$, diabetes mellitus $(15.9 \%)$, obesity (6.9\%), and COPD (5.7\%). The average hospital stay was 3.1 days during the first period and 2.65 days during the second period, with a non-significant decrease in the average hospital stay after implementation of the care bundle $(p=0.505)$. With respect to the moment of surgery, $83.8 \%$ of the interventions were scheduled, while $16.2 \%$ were emergency surgeries.

Pre-surgical preparation of the skin consists of three main items: body hygiene, hair removal, and surgical field antisepsis. Hair removal decreased from $17 \%$ to $9.1 \%$, and $76.9 \%$ of the patients were correctly prepared. Only $10.8 \%$ of the patients with adequate preparation developed an SSI, while the percentage of SSIs among patients with inadequate preparation rose to $17.3 \%(p=0.001)$. Antibiotic prophylaxis was correctly administered in $93.5 \%$ of patients and increased from $89.7 \%$ to $97.6 \%$ ( $p<0.05$ ), while $11.5 \%$ of patients who received proper antibiotic prophylaxis developed an SSI, 20.5\% in whom antibiotic prophylaxis was inappropriate became infected.

In terms of surgical approach, $28.8 \%$ of the interventions were performed by laparoscopy ( $21.9 \%$ during the pre-intervention period and $36.2 \%$ during the post-intervention period).

The types of surgery performed were as follows: right hemicolectomies (29.7\%); sigmoidectomies (21.9\%); total intra-abdominal colectomies (14.7\%); right hemicolectomies (12.3\%); colostomies (10.6\%); stomas closure $(9.6 \%)$; and resections of transverse colon (1.2\%). A breakdown of the type of surgical intervention performed by the risk of contamination showed that $88.8 \%$ were contaminated and $11.2 \%$ were dirty. With respect to the localization of SSIs, $71.4 \%$ were superficial, $13.6 \%$ were deep, and $14.1 \%$ were organ-space. The percentage of SSIs was as follows: $9.3 \%$ among patients with NISS 0; $11.5 \%$ among patients with NISS $1 ; 12.6 \%$ among patients with NISS 2; and $14.1 \%$ among patients with NISS 3. 
Figure 1. Etiology of infections.

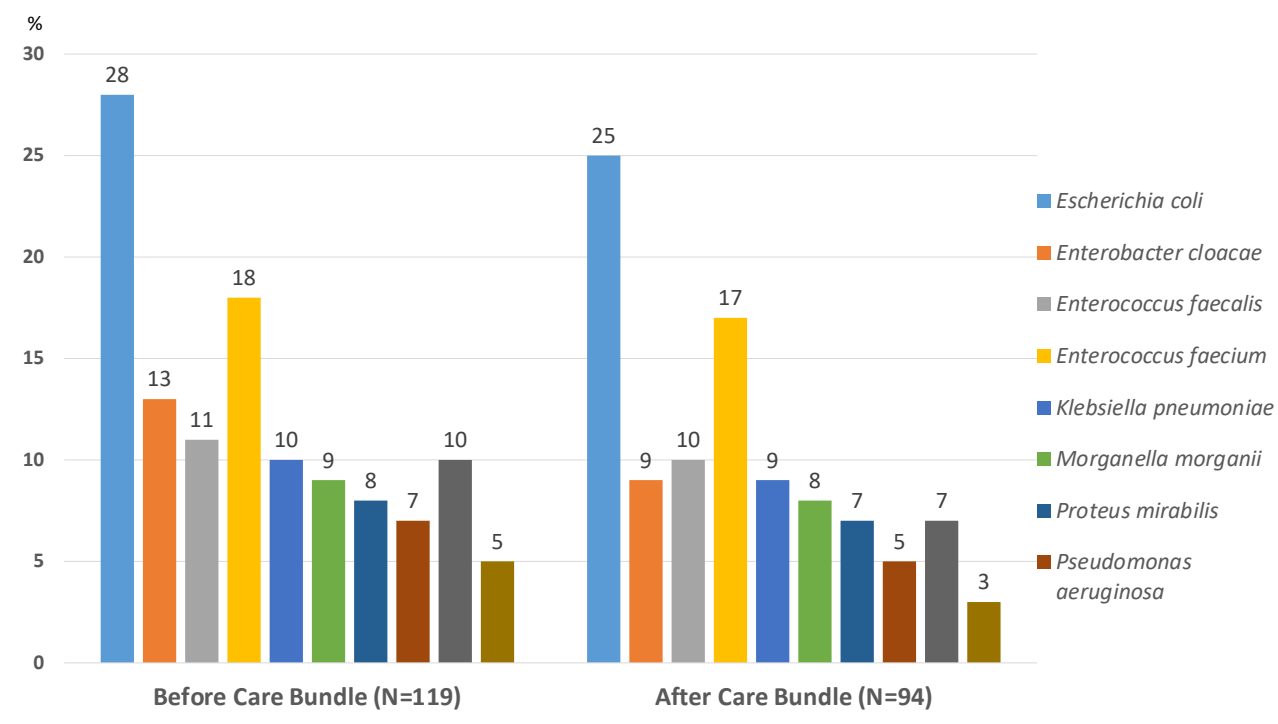

Figure 2. Effect of the surgical care bundle on surgical site infection incidence.

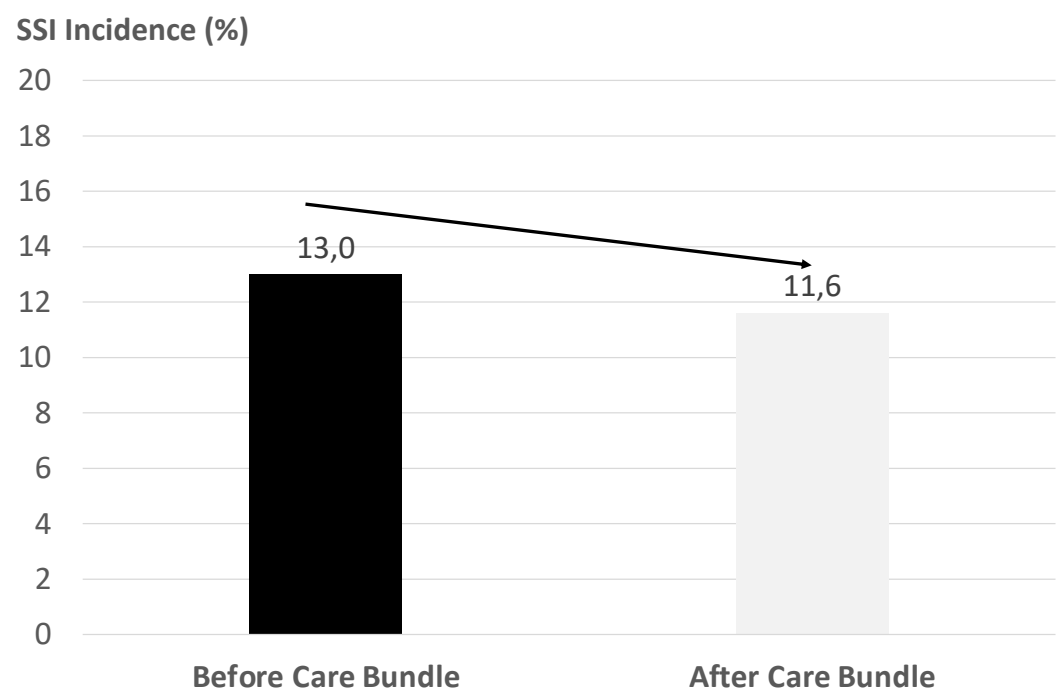

In the period 2006 through 2017, 213 patients who underwent colorectal surgery developed SSIs, with an overall incidence of $12.3 \%$. (95\% Cl: 10.9-14). The most frequent pathogenic microorganisms identified were Escherichia coli (26.3\%), Enterococcus faecium (12.7\%), Enterococcus faecalis (9.9\%), and Enterobacter cloacae (8.9\%). Microorganisms causing infection in both periods are shown in figure 1. Analysis of the results by reference to the two periods of the study indicated an SSI incidence of $13.0 \%$ before implementation of the care bundle; after implementation, SSI incidence decreased by some $1.4-11.6 \%$ (OR: $0.88,95 \% \mathrm{Cl}: 0.66-1.17, \mathrm{p}=0.37$ ) (Fig. 2).

The univariate and multivariate analyses are shown in Table 4. The multivariate analysis showed the following risk factors to be independently associated with SSI: COPD (OR: $2.10,95 \% \mathrm{Cl}: 1.26-3.49, \mathrm{p}=0.004$ ); immunodeficiency (OR: $3.59,95 \% \mathrm{Cl}: 1.19-10.83$, $\mathrm{p}=0.024$ ); and emergency surgery (OR: $1.86,95 \%$ $\mathrm{Cl}: 1.32-2.63, \mathrm{p}<0.001)$. In contrast, endoscopic 
Table 4. Univariate and multivariate analyses

\begin{tabular}{|c|c|c|c|c|}
\hline \multicolumn{5}{|c|}{ Univariate analysis } \\
\hline Risk factors & & OR & $95 \% \mathrm{Cl}$ & $\mathrm{p}$ \\
\hline Emergency surgery & & 2.05 & $1.47-2.88$ & 0.001 \\
\hline $\begin{array}{l}\text { Incorrect pre-surgical } \\
\text { preparation }\end{array}$ & & 1.72 & $1.26-2.35$ & 0.001 \\
\hline $\begin{array}{l}\text { Inadequate antibiotic } \\
\text { prophylaxis }\end{array}$ & & 1.98 & $1.30-3.01$ & 0.001 \\
\hline $\mathrm{COPD}^{\mathrm{a}}$ & & 2.18 & $1.33-3.59$ & 0.002 \\
\hline Neutropenia & & 3.62 & $1.22-10.7$ & 0.013 \\
\hline Obesity & & 1.68 & $1.03-2.74$ & 0,034 \\
\hline Laparoscopic surgery & & 0.42 & $0.28-0.61$ & 0.001 \\
\hline Cancer & & 1.51 & $1.11-2.23$ & 0.012 \\
\hline \multicolumn{5}{|c|}{ Multivariate analysis } \\
\hline Risk factors & Coef & OR & $95 \% \mathrm{Cl}$ & $\mathrm{p}$ \\
\hline COPD & 0.741 & 2.10 & $1.26-3.49$ & 0.004 \\
\hline Neutropenia & 1.278 & 3.59 & $1.19-10.83$ & 0.024 \\
\hline Laparoscopic surgery & -0.72 & 0.49 & $0.33-0.72$ & 0.0001 \\
\hline Emergency surgery & 0.621 & 1.86 & $1.32-2.63$ & 0.0001 \\
\hline Period (after) & -0.049 & 0.95 & $0.71-1.28$ & 0.75 \\
\hline Cancer & 0.712 & 1.489 & $1.18-2.01$ & 0.02 \\
\hline
\end{tabular}

COPD: Chronic Obstructive Pulmonary Disease. OR: odds ratio.

surgery, as shown by the univariate analysis, again proved to be a protective factor against SSI (OR: $0.49,95 \% \mathrm{Cl} 0.33-0.72, p<0.001)$.

\section{DISCUSSION}

Colorectal surgery is a surgical procedure with a high risk of $\mathrm{SSI}^{21}$, which registers a higher infection rate than other digestive system surgeries. In our study, the incidence of SSI after colorectal surgery was $12.3 \%$, a figure in line with recent data ${ }^{22-24}$. SSI incidence is a good indicator of improvement in healthcare quality and safety and accounts for the fact that actions grouped into preventive care bundles and targeted at preventing SSI have not only achieved a significant decrease in incidence but have also proved to be cost-effective ${ }^{8,25,26}$.

In Spain, previous experiences have provided evidence of a $10.9-1.9 \%(p<0.05)$ decrease in risk of SSI after application of a preventive care bundle in pediatric patients for heart surgery ${ }^{27}$, as well as a $27.5-16.9 \%$ $(p=0.03)$ drop in SSI recorded by a similar study on colorectal surgery ${ }^{2}$. Furthermore, other international reviews have reported favorable results similar to those described ${ }^{18,28-31}$. Our study observed a reduction in SSI from $13.0 \%$ to $11.6 \%$, amounting to a reduction in risk of $1.4 \%$ (OR: $0.88,95 \% \mathrm{Cl}: 0.66-$ 1.17).

In this respect, reductions of almost $84 \%$ in the risk of SSI in colon surgery have been described after implementation of different preventive care bundles, findings much higher than those reported by our study ${ }^{32}$. The components of our care bundle included measures to optimize antibiotic prophylaxis, appropriateness of patients' pre-operative preparation, reinforcement of hand hygiene promotion, shaving with electric razor, and the participation of members of the multidisciplinary group to ensure prolonged maintenance over time of the measures implemented. These measures are recommended by the Spanish Ministry of Health. No significant improvement 
$(p=0.75)$ was seen in SSI incidence after implementation of the care bundle.

Appropriateness of antibiotic prophylaxis went from $89.7 \%$ to $97.6 \%$, with timing of administration being the most frequent cause of inappropriateness, a finding in line with those of other SSI studies conducted in Spain ${ }^{33,34}$. There was a $17-9.1 \%$ reduction in hair removal, indicating heightened awareness of the need to remove hair only where this is essential ${ }^{35}$. Appropriateness of pre-operative preparation rose from $88.1 \%$ to $96.6 \%$. The recent study by Bagga et al. ${ }^{36}$ showed how implementation of a similar care bundle, including pre-operative bathing with chlorhexidine, hair removal with electric clippers, monitoring of antibiotic use, optimization of hand hygiene compliance, and intraoperative glycemic control, achieved reductions of $3.4 \%$ through $1.2 \%$ in SSI.

In addition, our study evaluated other possible risk factors, both intrinsic and extrinsic to the patient. In the univariate analysis, the following proved significant: cancer, emergency surgery, incorrect pre-surgical preparation, inappropriate antibiotic prophylaxis, COPD, neutropenia, and obesity. Obesity was considered of interest, given its clinical significance and prognosis as a risk factor for SSI, but neither obesity nor incorrect pre-surgical preparation nor inappropriate antibiotic prophylaxis was kept as risk factors in the multivariate analysis. Rather than diabetes per se, this may be more closely connected to the fact that what really predisposes patients to suffer infections is poor glycemic control of the disease; however, on not having access to the blood glucose levels of these patients, we have no way of confirming their baseline status for the purpose of establishing such an association $^{37,38}$. Laparoscopic surgery happened to be a protective factor against SSI, as described in the literature ${ }^{39,40}$

During the study period, some changes were introduced along with the implementation of the care bundle. Thus, antibiotic prophylaxis changed according to the continuous updating of the antibiotic prophylaxis protocol, the oral cathartic also changed, and the percentage of use of laparoscopic surgery grew. The fact that the effect of the care bundle was not statistically significant may be due to the confounding effect of the improvement in antibiotic prophylaxis, the change of the oral cathartic, and increased use laparoscopy.
The most frequent pathogenic microorganisms identified were Enterobacteriaceae, in line with the data published in the literature ${ }^{41}$.

In conclusion, care bundles have shown themselves to be vital in reducing the incidence of SSI since the measures that constitute these protocols are mutually reinforcing. To compare different cohorts across time is the best way to conduct such quasi-experimental protocols. Nowadays, it is not considered ethical to conduct a blinded study in which part of the patients is included in one arm with the care bundle and part is included in another arm without proper measures. In our study, the implementation of a care bundle reduced the incidence of infection from 13\% to $11.6 \%$, though there was no statistically significant difference between the pre-intervention period and after its implementation.

\section{ACKNOWLEDGMENTS}

The authors would like to thank Mr. Sergio Rodríguez Villar (Department of Preventive Medicine, Alcorcón Foundation University Hospital, Alcorcón, Madrid, Spain) for his support in recording the data and managing the database. They also extend their gratitude to the European Regional Development Fund (ERDF) and the Spanish Health Research Fund (Fondo de Investigación Sanitaria/ FIS) for supporting the research project PI19/00987, and the Alcorcón Foundation University Teaching Hospital for the HUFA 2018 grant, which enabled this study to be completed.

\section{REFERENCES}

1. Del Moral Luque JA, García MA, Yonte PG, Fernández-Cebrián JM, Durán-Poveda M, Rodríguez-Caravaca G. Incidence of surgical site infection in colon surgery and antibiotic prophylaxis adequacy: prospective cohort study. An Sist Sanit Navar. 2017;40:371-7.

2. Pérez-Blanco V, García-Olmo D, Maseda-Garrido E, Nájera-Santos MC, García-Caballero J. Evaluation of a preventive surgical site infection bundle in colorectal surgery. Cir Esp. 2015;93:222-8.

3. Arefian H, Hagel S, Fischer D, Scherag A, Brunkhorst FM, Maschmann J, et al. Estimating extra length of stay due to healthcare-associated infections before and after implementation of a hospital-wide infection control program. PLoS One. 2019; 14:e0217159.

4. Jenks PJ, Laurent M, McQuarry S, Watkins R. Clinical and economic burden of surgical site infection (SSI) and predicted financial consequences of elimination of SSI from an English hospital. J Hosp Infect. 2014;86:24-33.

5. Yokoe DS, Anderson DJ, Berenholtz SM, Calfee DP, Dubberke ER Ellingson KD, et al. A compendium of strategies to prevent healthcare-associated infections in acute care hospitals: 2014 updates. Infect Control Hosp Epidemiol 2014;35:967-77. 
6. Mangram AJ, Horan TC, Pearson ML, Silver LC, Jarvis WR. Guideline for prevention of surgical site infection, 1999. Centers for disease control and prevention (CDC) hospital infection control practices advisory committee. Am J Infect Control. 1999;27:97-132.

7. Koek MB, Wille JC, Isken MR, Voss V, van Benthem BH. Postdischarge surveillance (PDS) for surgical site infections: a good method is more important than a long duration. Euro Surveill. 2015;20:21042.

8. Anderson DJ, Podgorny K, Berríos-Torres SI, Bratzler DW, Dellinger EP, Greene L, et al. Strategies to prevent surgical site infections in acute care hospitals: 2014 update. Infect Control Hosp Epidemiol. 2014;35:605-27.

9. Awad SS. Adherence to surgical care improvement project measures and post-operative surgical site infections. Surg Infect (Larchmt). 2012;13:234-7.

10. Î́nigo JJ, Aizcorbe M, Izco T, De la Torre A, Usoz JJ, Soto JA. Vigilancia y control de la infección de sitio quirúrgico. An Sist Sanit Navar. 2000;23:129-41.

11. Bratzler DW, Dellinger EP, Olsen KM, Perl TM, Auwaerter PG, Bolon MK, et al. Clinical practice guidelines for antimicrobial prophylaxis in surgery. Surg Infect (Larchmt). 2013;14:73-156.

12. Ortega G, Rhee DS, Papandria DJ, Yang J, Ibrahim AM, Shore AD, et al. An evaluation of surgical site infections by wound classification system using the ACS-NSOIP. J Surg Res. 2012;174:33-8.

13. Tyrer J. Service improvement study to improve care for patients who developed a surgical site infection after discharge. $\mathrm{Br} \mathrm{J}$ Nurs. 2019:28:S6-19.

14. Tanner J, Khan D, Aplin C, Ball J, Thomas M, Bankart J. Postdischarge surveillance to identify colorectal surgical site infection rates and related costs. J Hosp Infect. 2009;72:243-50.

15. Pujol-Rojo M, Shaw-Perujo E. Surveillance of surgical site infections. What is the best way? Enferm Infecc Microbiol Clin. 2014; 32:477-8

16. Bratzler DW, Hunt DR. The surgical infection prevention and surgical care improvement projects: national initiatives to improve outcomes for patients having surgery. Clin Infect Dis. 2006;43:322-30

17. National Institute for Health and Clinical Excellence (NICE). London: Surgical Site Infection: prevention and Treatment; 2019. Available from: https://www.nice.org.uk/guidance/ng125/resources/surgical-site-infections-prevention-and-treatmentpdf-66141660564421. [Last accessed on 2020 Jul 31]

18. Waits SA, Fritze D, Banerjee M, Zhang W, Kubus J, Englesbe MJ, et al. Developing an argument for bundled interventions to reduce surgical site infection in colorectal surgery. Surgery. 2014; 155:602-6.

19. Tanner J, Padley W, Assadian O, Leaper D, Kiernan M, Edmiston C. Do surgical care bundles reduce the risk of surgical site infections in patients undergoing colorectal surgery? A systematic review and cohort meta-analysis of 8515 patients. Surgery. 2015:158:66-77

20. Available from: https://www.mscbs.gob.es/organizacion/sns/ plancalidadsns/docs/estrategia_sp_sns_2005_2011.pdf. [Last accessed on 2021 Apr 03].

21. Díaz-Agero-Pérez C, Pita-López MJ, Robustillo-Rodela A, et al. Assessment of the surgical site infection in 14 hospitals of the Madrid Region: an incidence study. Enferm Infecc Microbiol Clin. 2011:29:257-62

22. Kulkarni N, Arulampalam T. Laparoscopic surgery reduces the incidence of surgical site infections compared to the open approach for colorectal procedures: a meta-analysis. Tech Coloproctol. 2020:24:1017-24

23. Wu Q, Wei M, Ye Z, Bi L, Zheng E, Hu T, et al. Laparoscopic colectomy versus open colectomy for treatment of transverse colon cancer: a systematic review and meta-analysis. J Laparoendosc Adv Surg Tech A. 2017:27:1038-50.

24. Felsenreich DM, Gachabayov M, Rojas A, Latifi R, Bergamaschi R. Meta-analysis of postoperative mortality and morbidity after total abdominal colectomy versus loop ileostomy with colonic lavage for fulminant Clostridium difficile colitis. Dis Colon Rectum. 2020;63:1317-26

25. Leaper DJ, Holy CE, Spencer M, Chitnis A, Hogan A, Wright GW et al. Assessment of the risk and economic burden of surgical site infection following colorectal surgery using a US longitudinal database: is there a role for innovative antimicrobial wound closure technology to reduce the risk of infection? Dis Colon Rectum. 2020;63:1628-38.

26. Featherall J, Miller JA, Bennett EE, Lubelski D, Wang $H$, Khalaf $T$, et al. Implementation of an infection prevention bundle to reduce surgical site infections and cost following spine surgery. JAMA Surg. 2016;151:988-90.

27. Izquierdo-Blasco J, Campins-Martí M, Soler-Palacín P, Balcells J, Abella R, Gran F, et al. Impact of the implementation of an interdisciplinary infection control program to prevent surgical wound infection in pediatric heart surgery. Eur J Pediatr. 2015; 174:957-63.

28. Crolla RM, van der Laan L, Veen EJ, Hendriks Y, van Schendel C, Kluytmans J. Reduction of surgical site infections after implementation of a bundle of care. PLoS One. 2012;7:e44599.

29. Lutfiyya W, Parsons D, Breen J. A colorectal "care bundle" to reduce surgical site infections in colorectal surgeries: a singlecenter experience. Perm J. 2012;16:10-6.

30. Wick EC, Hobson DB, Bennett JL, Demski R, Maragakis L, Gearhart SL, et al. Implementation of a surgical comprehensive unitbased safety program to reduce surgical site infections. J Am Coll Surg. 2012;215:193-200.

31. Keenan JE, Speicher PJ, Thacker JK, Walter M, Kuchibhatla M Mantyh CR. The preventive surgical site infection bundle in colorectal surgery: an effective approach to surgical site infection reduction and health care cost savings. JAMA Surg. 2014; 149:1045-52.

32. Harris J. Success of a colorectal surgical site infection prevention bundle in a multihospital system. AORN J. 2018;107:592-600.

33. Rodríguez-Caravaca G, Del Campo MC, González-Díaz R, Martínez-Martín J, Toledano-Muñoz A, Durán-Poveda M. Compliance with antibiotic prophylaxis in spinal fusion surgery and surgical wound infection. Rev Invest Clin. 2014:66:484-9.

34. Díaz-Agero Pérez C, Rodela AR, López MJ, Fresneña NL, Jodrá VM; Quality Control Indicator Working Group. Surgical wound infection rates in Spain: data summary, January 1997 through June 2012. Am J Infect Control. 2014;42:521-4.

35. Berríos-Torres SI, Umscheid CA, Bratzler DW, Leas B, Stone EC, Kelz RR, et al. Centers for disease control and prevention guideline for the prevention of surgical site infection, 2017. JAMA Surg. 2017;152:784-91.

36. Bagga RS, Shetty AP, Sharma V, Sri Vijayanand KS, Kanna RM, Rajasekaran $\mathrm{S}$. Does preventive care bundle have an impact on surgical site infections following spine surgery? An analysis of 9607 patients. Spine Deform. 2020;8:677-84.

37. Ghuman A, Chan T, Karimuddin AA, Brown CJ, Raval MJ, Phang PT. Surgical site infection rates following implementation of a colorectal closure bundle in elective colorectal surgeries. Dis Colon Rectum. 2015;58:1078-82

38. Weiser MR, Gonen M, Usiak S, Pottinger T, Samedy P, Patel D, et al. Effectiveness of a multidisciplinary patient care bundle for reducing surgical-site infections. Br J Surg. 2018;105:1680-7.

39. Nasser $\mathrm{H}$, Ivanics $\mathrm{T}$, Leonard-Murali S, Stefanou A. Risk factors for surgical site infection after laparoscopic colectomy: an NSQIP database analysis. J Surg Res. 2020;249:25-33.

40. Nakamura T, Takayama Y, Sato T, Watanabe M. Risk Factors for wound infection after laparoscopic surgery for colon cancer. Surg Laparosc Endosc Percutan Tech. 2020;30:45-8.

41. Kalakouti E, Simillis C, Pellino G, Mughal N, Warren O, Mills S, et al. Characteristics of surgical site infection following colorectal surgery in a tertiary center: extended-spectrum beta-Lactamase-producing bacteria culprits in disease. Wounds. 2017; 30:108-13. 